\title{
Development of a sublingual allergy vaccine for grass pollinosis
}

This article was published in the following Dove Press journal:

Drug Design, Development and Therapy

15 June 2010

Number of times this article has been viewed

\section{Franco Frati ${ }^{1,2}$ \\ Silvia Scurati ${ }^{1}$ \\ Paola Puccinelli' \\ Marie David ${ }^{3}$ \\ Cecile Hilaire ${ }^{4}$ \\ Maurizio Capecce ${ }^{4}$ \\ Francesco Marcucci $^{2}$ \\ Cristoforo Incorvaia ${ }^{5}$}

'Medical and Scientific Department, Stallergenes, Milan, Italy; ${ }^{2}$ University Department of Medical and Surgical Specialties and Public Health, Perugia, Italy; ${ }^{3}$ Laboratoire Stallergenes,

Antony, France; ${ }^{4}$ Marketing

Department, Stallergenes, Milan, Italy;

${ }^{5}$ Allergy/Pulmonary Rehabilitation

Unit, ICP Hospital, Milan, Italy
Correspondence: Cristoforo Incorvaia Allergy/Pulmonary Rehabilitation Unit, ICP Hospital, via Bignami I, Milan, Italy Tel +390257993289

Fax +39025 7993315

Email cristoforo.incorvaia@gmail.com
Abstract: Grass pollen is a very common cause of allergic rhinitis and asthma. The only treatment targeting the underlying causes of allergy is immunotherapy (IT). Sublingual immunotherapy (SLIT) has been introduced to solve the problem of systemic reactions to subcutaneous IT (SCIT). This article evaluates the characteristics of the allergen extract, Staloral, in terms of practical administration, effectiveness, safety, and mechanism of action. Efficacy data were obtained from double-blind, placebo-controlled studies using Staloral in patients sensitized to grass pollen, while practical administration, cost-effectiveness, and mechanism of action data were provided by well designed studies. The efficacy and safety of Staloral, as demonstrated by review of published studies which used doses up to 1125 times those administered with SCIT, shows that this allergen extract has optimal characteristics for treating patients with seasonal allergies due to grass pollens. The main mechanism of action is the interaction between dendritic cells of the oral mucosa and the subsequent tolerance induced in T-cells.

Keywords: allergen extracts, high-dose, efficacy, safety, sublingual immunotherapy

\section{Introduction}

Grass pollen is a major source of respiratory allergy throughout the world. ${ }^{1,2}$ Grasses include a high number of species, which have variable importance in different geographical areas. In Europe, Dactylis glomerata, Poa pratensis, Lolium perenne, and Anthoxantum odoratum are homogeneously distributed, while Phleum pratense is the dominant grass in Northern regions and in the UK, and Cynodon dactylon occurs only in Southern regions (Table 1). In the US, the species cited above are diffusely spread, while $C$. dactylon is present only in the Northeast, Midwestern, and South/Southeast regions.

Allergy to grass pollen can be treated by symptomatic drugs, namely antihistamines, topical and systemic corticosteroids, and antileukotrienes, but only specific immunotherapy (IT) is able to act on the cause of allergy and to modify the natural history of the disease. ${ }^{3}$ IT was introduced in $1910,{ }^{4}$ demonstrated to be effective by a controlled trial in $1954,{ }^{5}$ and established further as effective in meta-analyses of studies of traditional, subcutaneous immunotherapy (SCIT), ${ }^{6,7}$ as well as sublingual immunotherapy (SLIT). ${ }^{8}$ Most immunotherapy studies were performed using extracts containing multiple grasses, but there are trials using only $D$. glomerata, $P$. pratense, or L. perenne, on the basis that they have all the relevant grass allergens. However, thus far, there are no immunologic data demonstrating that extracts of single grasses are equivalent to multiple grass extracts in terms of IgE-binding capacity in sera from grass allergic patients. This suggests that multiple grass extracts may fit better with individual patients' patterns of sensitization. ${ }^{9}$ 
Table I Distribution of grass species in Europe

\begin{tabular}{|c|c|c|c|c|c|c|}
\hline Geographic areas & $\begin{array}{l}\text { Lolium } \\
\text { perenne L. }\end{array}$ & $\begin{array}{l}\text { Poa } \\
\text { pratensis L. }\end{array}$ & $\begin{array}{l}\text { Phleum } \\
\text { pratense L. }\end{array}$ & $\begin{array}{l}\text { Dactylis } \\
\text { glomerata L. }\end{array}$ & $\begin{array}{l}\text { Anthoxanthum } \\
\text { odoratum L. }\end{array}$ & Climate \\
\hline Northern Europe & +++ & ++ & +++ & +++ & +++ & Oceanic, humid \\
\hline Mid Europe & +++ & ++ & +++ & +++ & ++ & Continental \\
\hline \multirow[t]{2}{*}{ Southern Europe } & ++ to +++ & +++ & + & + to ++ & + & Mediterranean, warm and dry \\
\hline & \multicolumn{2}{|c|}{ Species homogeneously } & \multicolumn{4}{|c|}{$\begin{array}{l}\text { Species less present in Southern Europe } \\
\text { than in Northern Europe }\end{array}$} \\
\hline
\end{tabular}

Notes: +++ highly frequent; ++ moderately frequent; + limited presence; - absence.

Allergen extracts to be used for IT should have all the relevant allergens from the naturally occurring source, in a known and reproducible composition. For many years extracts used for SCIT were measured in arbitrary units or in protein nitrogen units, but in the 1990s SLIT was introduced as a consequence of allergen extract standardization, that is, with a known composition, and constantly reproducible on a lot-to-lot basis, thereby ensuring adequate quality of allergen products. ${ }^{10}$ Availability of highquality, standardized extracts meets the need for indications of IT, ie, moderate to severe rhinitis and mild to moderate asthma. ${ }^{3}$ This paper describes the development of a standardized grass pollen extract (Staloral, Stallergenes, Antony, France) for the treatment of grass pollen-induced rhinitis and asthma.

\section{Standardization of Staloral}

The process of standardization is summarized in Figure 1. The index of reactivity (IR) is the biologic unit used; a concentration of 100 IR is determined by the capacity of the allergen to elicit by skin prick test a geometric mean wheal size of $7 \mathrm{~mm}$ diameter in 30 patients sensitized to the corresponding allergen. During the standardization procedure, the material is in the liquid phase. The product must be stored between $2^{\circ} \mathrm{C}$ and $8^{\circ} \mathrm{C}$. At room temperature, the extract is stable for three months.

Several allergen extracts for SLIT are currently marketed in Europe, and vary in the amount of allergens contained. Almost all of the commercially available SLIT vaccines in Europe are standardized biologically or immunologically, ${ }_{11}^{11}$ but because the standardization methods are based upon in-house references, the different extracts are labeled in units that differ from manufacturer to manufacturer. On the other hand, during the last few years, labelling of the content of major allergens in $\mu \mathrm{g}$ has been a significant improvement, enabling a rough comparison of different therapeutic regimens.

\section{Practical administration}

SLIT allergen extract solution can be delivered by dropcounters, pre-dosed actuators (mini-pumps), or disposable single-dose vials. Staloral100 IR was initially administered by a drop-counter, but subsequently a mini-pump pre-dosed actuator was introduced, and is the same as the one used for Staloral 300 IR. The allergen extract is usually taken in the morning before breakfast, is kept under the tongue for few minutes, and then swallowed. The acronym SLIT, unless otherwise stated, indicates the sublingual-swallow modality.

\section{Administration regimens}

SLIT traditionally involves an uptitration phase followed by maintenance treatment with the maximal dose. ${ }^{8}$ In the past the uptitration phase has lasted 4-6 weeks, but this has progressively been shortened. The extract is available in vials at concentrations of 10,100 , and 300 IR. Other concentrations are available for sensitized patients. The patient must start with the lowest concentration and gradually increase, according to the physician's prescription, until the maintenance dose is reached. Rush and ultra-rush inductions have also been proposed for routine use, based on the favorable safety profile of Staloral, including in children under the age of five years. ${ }^{12}$ Ultra-rush schemes with a build-up shorter than two hours have been reported in adults ${ }^{13}$ and children, ${ }^{14}$ with satisfactory results.

The maintenance dose is generally the same for all patients, based on clinical results. The maintenance dose recommended for Staloral is eight pressures corresponding to $16.8 \mu \mathrm{g}$ of the major allergen $\mathrm{Phl} \mathrm{p} 5$ for six months/year.

The use of the same dose for all patients is justified on the basis that, in contrast with SCIT, the administration of very high amounts of allergens does not provoke severe side effects. The maintenance dose could be administered at variable time intervals but the once-daily simplifies the regimen by assuming the dose as done with almost all drugs.

\section{Criteria for starting and stopping treatment}

Staloral can be administered either pre-coseasonally (starting 2-4 months before and stopping at the end of the pollen season), coseasonally (only during the pollen season), or continuously. ${ }^{15}$ In the pre-co-seasonal and co-seasonal regimen, no dose reduction during the pollen season is usually necessary, since 


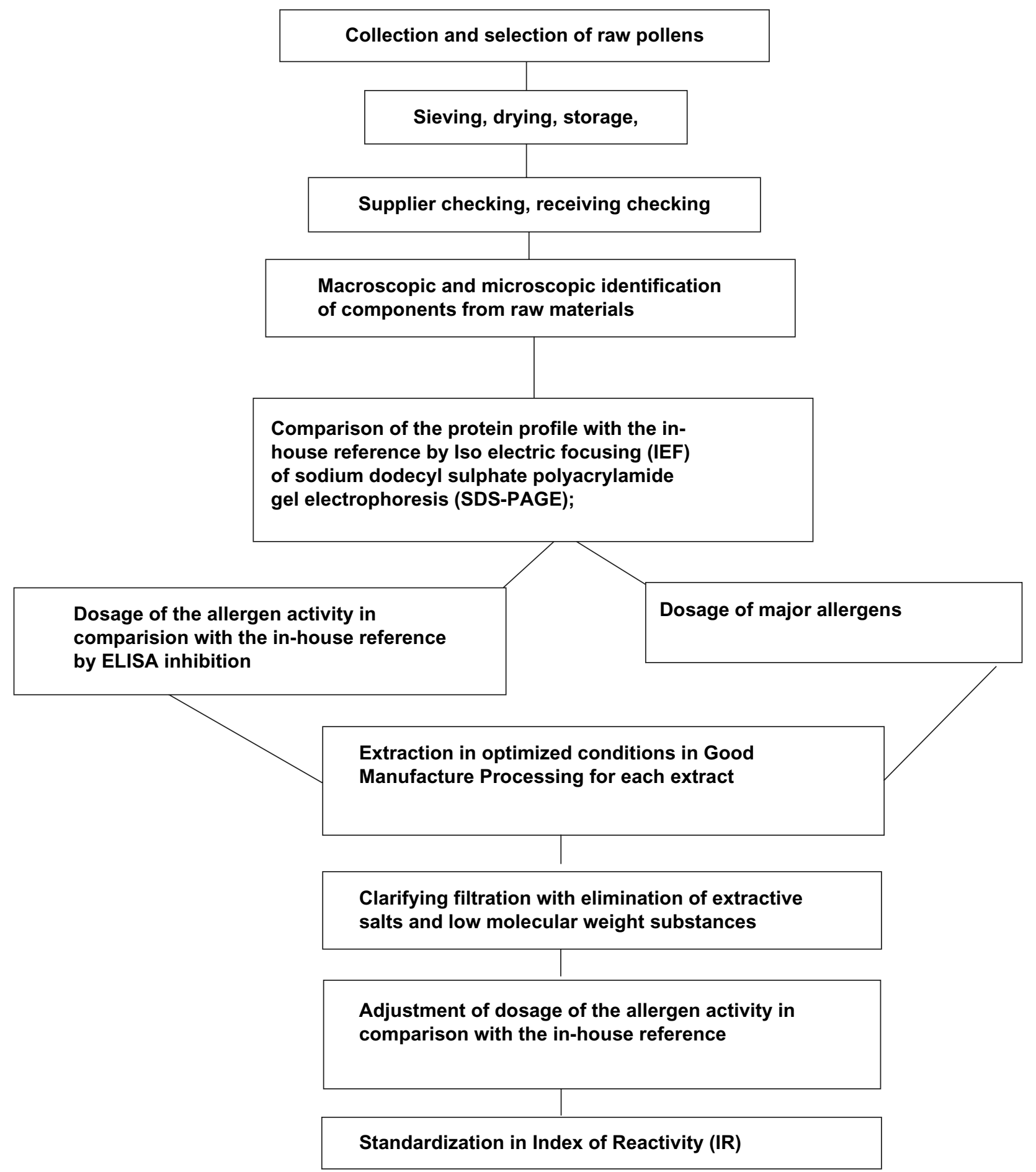

Figure I Process of standardization of Staloral 300.

there is no decrease in safety. ${ }^{16} \mathrm{~A}$ recent study reported that a coseasonal schedule of $300 \mathrm{IR} /$ day for three years had a carryover effect following Staloral discontinuation. ${ }^{17}$

\section{Clinical efficacy}

The first studies on SLIT used very low or low doses, ${ }^{18}$ but it subsequently became apparent that 50- to 100-fold higher doses than those administered for SCIT were needed to ensure clinical efficacy, ${ }^{19}$ thereby introducing the concept of "high-dose SLIT". Staloral can be classified in this category because the ratio with the extract used for SCIT is higher than 50 (in most studies higher than 300) for any allergen used. Thus far, the results of eight studies of SLIT with grass pollen are available, all demonstrating significantly lower mean symptom/medication 
scores in adult patients ${ }^{20-24}$ and children ${ }^{17,21,25,26}$ treated with Staloral compared with placebo-treated controls.

Table 2 reports the main data from the published studies evaluating Staloral for grass pollen allergy. In one additional, randomized, open-label study, different doses of Staloral were compared, demonstrating that the 300 IR maintenance dose had optimal effectiveness in terms of immunologic response. ${ }^{27}$

\section{Cost-effectiveness}

Currently, cost-effectiveness is an important issue in health care. Some studies have addressed this question in SLIT treatment with Staloral. The first published study evaluated the cost-effectiveness of SLIT in 135 children with allergic rhinitis and asthma ( 89 of whom were sensitized to grass pollen) by assessing direct costs (drugs, specialists visits, and SLIT) and indirect costs (costs resulting from absences from school and work). A substantial reduction was found in all outcome measures after the start of SLIT treatment, indicating that high-dose SLIT may be effective in reducing the economic burden of allergic rhinitis and asthma. ${ }^{28}$

A second study was done using a decision tree populated with epidemiologic and resource utilization data for approximately 2200 adults with pollen allergy attending 25 Italian centers over a six-year period. ${ }^{29}$ Assessment criteria for the pharmacoeconomic analysis included direct medical costs from the National Health Service perspective (ie, visits, diagnostic procedures, drugs, SLIT, and hospitalizations), and indirect costs (lost working days and patient out-of-pocket expenses) from the societal perspective. Endpoints used for effectiveness included number of patients improved by treatment and number of asthma cases avoided. Finally incremental costs per improved patient and incremental costs per asthma case avoided were measured. A mean cost per patient treated over a period of six years was calculated for each therapeutic strategy and for each of the two perspectives studied. The SLIT strategy resulted in less expense in term of both direct and indirect costs. The break-even point of SLIT, ie, the time at which the overall cost of treatment for SLIT patients becomes lower than for patients receiving drugs only for the societal perspective was reached at four years.

A third pharmacoeconomic study evaluated SLIT in patients with pollen allergy and suffering from allergic rhinitis alone or in association with asthma compared with standard case-controls. ${ }^{30}$ This study used a longitudinal observational database operated by a network of allergy centers. Patients were randomly assigned to SLIT (plus drugs as needed) or to treatment with drugs alone. The outcome measures included use of drugs, SLIT, visits, and tests. Costs were assessed from the Italian National Health Service perspective. The results showed that the overall per patient yearly cost of treatment was higher in SLIT patients than in those who received drugs alone, both in the whole sample (€311 versus $€ 180$ per patient, respectively), and in the rhinitis (€288 versus $€ 116$ ) and rhinitis associated with asthma (€362 versus €230) subgroups. Patients with both rhinitis and asthma generated more costs than those with rhinitis alone in both groups. Nevertheless, considerable savings were made in terms of the cost of drugs used to treat symptoms ( $-22 \%$ for rhinitis, $-34 \%$ for rhinitis and asthma) in SLIT patients. Previous efficacy studies $^{8}$ have shown that SLIT can reduce the use of drugs for symptomatic relief, but this is the earliest research demonstrating this outcome in a patient population seen in routine clinical practice during the first year of treatment.

These studies indicate that SLIT may be beneficial to the health care system, in that it could bring more clinical effectiveness at a reduced cost in comparison with standard drug treatment, as well as have the potential to accrue extra benefit at an acceptable additional cost. ${ }^{31}$

\section{Safety and tolerability}

SLIT was developed with the specific goal of improving safety and this issue is of particular importance. As demonstrated in

Table 2 Published studies of SLIT with Staloral grass pollen

\begin{tabular}{|c|c|c|c|c|c|}
\hline Reference & Maintenance & Protocol & Treatment duration & $\begin{array}{l}\text { Major allergen } \\
\text { mean dose/month }\end{array}$ & SLIT/SCIT ratio \\
\hline 20 & Daily & Pre-coseasonal & 4 months & $210 \mathrm{Dac} g \mathrm{~g}$ & 50 \\
\hline 21 & Daily & Pre-coseasonal & 6 months & $433.3 \mu \mathrm{g}$ Phl p 5 & 500 \\
\hline 22 & Daily & Pre-coseasonal & 4 months & $233.8 \mu \mathrm{g}$ Phl p 5 & 150 \\
\hline 25 & Alternate days & Continuous & 12 months & $210 \mu \mathrm{g}$ Dac g 5 & 150 \\
\hline 23 & Alternate days & Pre-coseasonal & 2 years & $329 \mu \mathrm{g}$ Dac g 5 & 450 \\
\hline 24 & Daily & Continuous & 9 months & $388 \mu g$ Phl p 5 & 1125 \\
\hline 17 & Daily & Coseasonal & 3 years & $500 \mu g$ Phl p 5 & 1125 \\
\hline 26 & Daily & Pre-coseasonal & 2 years & $304 \mu \mathrm{g}$ Phl p 5 & 450 \\
\hline
\end{tabular}

Abbreviations: SLIT, sublingual immunotherapy; SCIT, subcutaneous immunotherapy. 
the literature, the majority of adverse events involve the site of contact with the allergen extract, ie, the mouth and both upper and lower digestive systems. Most adverse events can be easily managed by dose modification (eg, in the event of disturbing gastrointestinal reactions, by spitting out the extract after having kept it under the tongue for 2-3 minutes). It should be noted that SLIT is not generally used under medical supervision, whereas reporting of side effects is higher in clinical trials and post-marketing surveillance.

Importantly, no fatality has ever been described in association with SLIT. Most local side effects are described as mild and self-resolving without dose adjustment or medical intervention. SLIT must be discontinued very rarely. Systemic side effects (eg, asthma, rhinitis, urticaria, angioedema) have been reported only occasionally in the available controlled studies.

In 2000, André et al examined the safety of SLIT in the eight trials performed with Staloral at that time. ${ }^{32}$ These studies involved 690 subjects (347 on active treatment and 343 on placebo), including 218 children aged 5-16 years (103 active and 115 placebo). The majority of adverse events were mild and their occurrence did not differ between the active and placebo groups. The only differences were for oral and gastrointestinal side effects that were more frequent in SLIT patients, although mild. Adverse event and dropout rates were similar in adults and children.

In 2005 a systematic review of the relevant published studies evaluated dose-related adverse event rates, expressed as the ratio between SLIT and the equivalent SCIT. ${ }^{33}$ In total, 25 studies were analyzed, of which 13 studies had used low doses (doses ranging from one to 50 times the dose commonly administered with SCIT), and 12 had used high doses (doses ranging from 50 to 500 times the dose administered with SCIT). Local reactions were significantly more frequent in the low-dose group than in the high-dose group $(P<0.0001)$, but there was no difference in systemic reaction rates between low- and highdose groups. No severe systemic reactions were reported. This review provided evidence that the occurrence of side effects during SLIT, unlike with SCIT, is not dose-dependent.

Very recently, two cases of anaphylaxis to an alternative grass pollen tablet were reported, ${ }^{34}$ along with two respiratory reactions to the grass pollen tablet manufactured Stallergenes, ${ }^{35}$ all occurring in patients who had experienced previous systemic reactions to SCIT. These reports suggest that poor tolerance of SCIT may need to be considered as a potential contraindication to use of SLIT. ${ }^{36}$

The question of use of high-dose SLIT in children younger than five years (which is the age cut-off for SCIT) has also been addressed. An observational safety study has been done in 65 children treated with SLIT using an uptitration phase of 11 days and culminating in a maximal maintenance dose of 300 IR three times a week. ${ }^{12}$ Grass pollen was the second most frequently used allergen (after house dust mites). Adverse event rates and changes in the treatment schedule were compared in children younger or older than five years. The average cumulative dose of SLIT was 36,900 IR. Adverse reactions were observed in 11 children, none of which were severe enough to require discontinuation of immunotherapy. Six adverse reactions occurred in children younger than five years and seven in the older children. This difference was not considered significant.

\section{Mechanism of action}

The prophylactic and therapeutic effects of immunotherapy are related to its mechanism of action. ${ }^{37}$ In particular, immunotherapy reduces allergic inflammation even after its discontinuation, and so modifies the natural history of the allergy. Such anti-inflammatory effects, exerted also by SLIT, are based on the ability of immunotherapy to modify the phenotype of T-cells, which in allergic subjects is characterized by a prevalence of the Th2 type, with production of IL (interleukin)-4, IL-5, IL-13, IL-17, and IL-32 cytokines. ${ }^{37}$ The induced changes result in a Th1-type response (immune deviation) related to increased IFN-gamma and IL-2 production or to reduced Th2 activity, through a mechanism of anergy or tolerance. It is now known that T-cell tolerance is characterized by the generation of allergen-specific regulatory T-cells (Treg cells), which produce cytokines, such as IL-10 and transforming growth factor-beta, with immunosuppressant and/or immunoregulatory activity. ${ }^{38}$ Recent studies suggest that the antinflammatory mechanism of SLIT is similar to that of classical, subcutaneous IT, ${ }^{39}$ with mucosal dendritic cells having a prominent role in SLIT. Of note, it has been found in in vitro experiments that internalization of allergens by Langerhanslike dendritic cells is dose-dependent. ${ }^{40}$ The tolerance pattern promoted by dendritic cells and driven by Treg should account for the suppressed or reduced activity of inflammatory cells and for the isotypic switch of antibody synthesis from $\operatorname{IgE}$ to $\mathrm{IgG}$, and especially to $\mathrm{IgG}_{4}$. The dose-dependence of the immunologic response has also been demonstrated in clinical studies of patients treated with Staloral 300. ${ }^{27}$ Moreover, data obtained from biopsies indicate that the oral mucosa plays a pivotal role in inducing tolerance to the sublingually administered allergen. In fact, in subjects treated with highdose grass pollen Staloral 300 SLIT, pretreatment biopsies 
Table 3 Advantages and disadvantages of SLIT compared with SCIT

\begin{tabular}{llc}
\hline Issues & SLIT & SCIT \\
\hline Efficacy & ++ & +++ \\
Safety & +++ & +- \\
Tolerability & ++ & ++ \\
Cost-effectiveness & +++ & ++- \\
Compliance & +++ & ++- \\
Long lasting effect & ++ & +++ \\
\hline
\end{tabular}

Abbreviations: SLIT, sublingual immunotherapy; SCIT, subcutaneous immunotherapy.

showed very low numbers of mast cells and eosinophils (ie, the effector cells of allergic reactivity) both in the epithelium and subepithelium layers, and insignificant changes were detected after SLIT. ${ }^{41}$

\section{Conclusion}

SLIT is a safe and effective therapeutic alternative to SCIT for allergen immunotherapy (Table 3). Staloral is an effective treatment for rhinitis and asthma attributable to sensitization to grass pollen. It is now generally accepted that allergen doses much higher than those administered by SCIT must be used to control allergic symptoms. Such doses can be administered in view of the reassuring data on tolerability and safety of high-dose SLIT. The efficacy and safety of Staloral, as demonstrated by eight double-blind, placebo-controlled studies using doses up to 1125 times higher than those administered with SCIT, ${ }^{17,20-26}$ suggests that this allergen extract is an attractive therapeutic option for patients with seasonal allergies due to grass pollen.

\section{Disclosure}

The authors report no conflicts of interest in this work.

\section{References}

1. D'Amato G, Cecchi L, Bonini S, et al. Allergenic pollen and pollen allergy in Europe. Allergy. 2007;62:976-990.

2. Freye HB. The role of pollens in allergy. Med Health R I. 2008;91: 174-175.

3. Bousquet J, Lockey R, Malling HJ, editors. World Health Organization Position Paper. Allergen immunotherapy: Therapeutic vaccines for allergic diseases. Allergy.1998;53 Suppl 52:3-15.

4. Noon L. Discussion on vaccine therapy: Its treatment, value, and limitations. Proc R Soc Med. 1910;3:161-164.

5. Frankland AW, Augustin R. Prophylaxis of summer hay-fever and asthma: A controlled trial comparing crude grass-pollen extracts with the isolated main protein component. Lancet. 1954;266:1055-1057.

6. Abramson MJ, Puy RM, Weiner JM. Allergen immunotherapy for asthma. Cochrane Database Syst Rev. 2003;(4):CD001186.

7. Calderon M, Alves B, Jacobson M, Hurvitz B, Sheikh A, Durham S. Allergen injection immunotherapy for seasonal allergic rhinitis. Cochrane Database Syst Rev. 2007;(1):CD001936.

8. Wilson DR, Torres-Lima M, Durham S. Sublingual immunotherapy for allergic rhinitis: Systematic review and meta-analysis. Allergy. 2005;60:4-12.
9. Moingeon P, Hrabina M, Bergmann KC, et al. Specific immunotherapy for common grass pollen allergies: Pertinence of a five grass pollen vaccine. Int Arch Allergy Immunol. 2008;146:338-342.

10. Platts Mills TA, Chapman MD. Allergen standardization. J Allergy Clin Immunol. 1991;87:621-625.

11. Becker WM, Vogel L, Vieths S. Standardization of allergen extracts for immunotherapy: Where do we stand? Curr Opin Allergy Clin Immunol. 2006;6:470-475.

12. Fiocchi A, Pajno G, La Grutta S, et al. Safety of SLIT in children aged 3 to 7 years. Ann Allergy Asthma Immunol. 2005;95:254-258.

13. Rossi R, Monasterolo RE. A pilot study of feasibility of ultra-rush (20-25 minutes) sublingual-swallow immunotherapy in 679 patients (699 sessions) with allergic rhinitis and/or asthma. Int J Immunopathol Pharmacol. 2005; 18:277-285.

14. Tripodi S, Di Rienzo Businco A, Benincori N, et al. Safety and tolerability of ultra-rush induction, less than one hour, of sublingual immunotherapy in children. Int Arch Allergy Immunol. 2005;139:149-152.

15. Lombardi C, Incorvaia C, Braga M, Senna GE, Canonica GW, Passalacqua G. Administration regimens for sublingual immunotherapy to pollen allergens: What do we know? Allergy. 2009;64:849-854.

16. Ariano R, Incorvaia C, La Grutta S, et al. Safety of sublingual immunotherapy started during the pollen season. Curr Med Res Opin. 2009:25:103-107.

17. Ott H, Sieber J, Brehler R, et al. Efficacy of grass pollen sublingual immunotherapy for three consecutive seasons and after cessation of treatment: The ECRIT study. Allergy. 2008;64:1394-1401.

18. Canonica GW, Passalacqua G. Noninjection routes for immunotherapy. J Allergy Clin Immunol. 2003;111:437-448.

19. Bousquet J, Van Cauwenberge P, editors. Allergic Rhinits and its Impact on Asthma (ARIA). J Allergy Clin Immunol. 2001;108 Suppl 5: S146-S150.

20. Sabbah A, Hassoun S, Le Sellin J, et al. A double-blind, placebo-controlled trial by the sublingual route of immunotherapy with a standardized grass pollen extract. Allergy. 1994;49:309-313.

21. Clavel R, Bousquet J, André C. Clinical efficacy of sublingual-swallow immunotherapy: A double-blind, placebo controlled trial of a standardized five grass-pollen extract in rhinitis. Allergy. 1998;53:493-498.

22. Pradalier A, Basset D, Claudel A, et al. Sublingual-swallow immunotherapy (SLIT) with a standardized five-grass-pollen extract (drops and sublingual tablets) versus placebo in seasonal rhinitis. Allergy. 1999;54:819-828.

23. Smith H, White P, Annila I, et al. Randomized controlled trial of high-dose sublingual immunotherapy to treat seasonal allergic rhinitis. J Allergy Clin Immunol. 2004;114:831-837.

24. Mosges R, Bruning H, Hessler HJ, et al. Sublingual immunotherapy in pollen-induced seasonal rhinitis and conjunctivitis: A randomized controlled trial. Acta Dermatovenerol Alp Panonica Adriat. 2007; 16:143-148.

25. Yuksel H, Tanac R, Gousseinov A, et al. Sublingual immunotherapy and influence on urinary leukotrienes in seasonal pediatric allergy. J Investig Allergol Clin Immunol. 1999;9:305-313.

26. Stelmach I, Kaczmarek-Wozniac J, Majac P, et al. Efficacy and safety of high-doses sublingual immunotherapy in ultra-rush scheme in children allergic to grass pollen. Clin Exp Allergy. 2009;39:401-408.

27. Marcucci F, Sensi L, Di Cara G, et al. Dose dependence of immunological response to sublingual immunotherapy. Allergy. 2005;60:952-956.

28. Berto P, Bassi M, Incorvaia C, et al. Cost effectiveness of sublingual immunotherapy in children with allergic rhinitis and asthma. Eur Ann Allergy Clin Immunol. 2005;37:303-308.

29. Berto P, Passalacqua G, Crimi N, et al. Economic evaluation of sublingual immunotherapy vs symptomatic treatment in adults with pollen-induced respiratory allergy: The Sublingual Immunotherapy Pollen Allergy Italy (SPAI) study. Ann Allergy Asthma Immunol. 2006;97:615-621.

30. Berto P, Frati F, Incorvaia $C$, et al. Comparison of costs of sublingual immunotherapy and drug treatment in grass-pollen induced allergy: Results from the SIMAP database study. Curr Med Res Opin. 2008;24:261-266. 
31. Berto P, Frati F, Incorvaia C. Economic studies of immunotherapy: A review. Curr Opin Allergy Clin Immunol. 2008;8:585-589.

32. André C, Vatrinet $\mathrm{C}$, Galvain $\mathrm{S}$, et al. Safety of sublingual swallow immunotherapy in children and adults. Int Arch Allergy Immunol. 2000;121:229-234.

33. Gidaro GB, Marcucci F, Sensi L, et al. The safety of sublingual-swallow immunotherapy: An analysis of published studies. Clin Exp Allergy. 2005;35:565-571.

34. de Groot H, Bijl A. Anaphylactic reaction after the first dose of sublingual immunotherapy with grass pollen tablet. Allergy. 2009;64:963-964.

35. Cochard MM, Eigenmann PA. Sublingual immunotherapy is not always a safe alternative to subcutaneous immunotherapy. JAllergy Clin Immunol. 2009;124:378-379.

36. Incorvaia $\mathrm{C}$, Mauro M. Do indications to sublingual immunotherapy need to be revised? J Allergy Clin Immunol. 2010;125:277.
37. Akdis M, Akdis CA. Mechanisms of allergen-specific immunotherapy J Allergy Clin Immunol. 2007;119:780-791.

38. Taylor A, Verhagen J, Blaser K, et al. Mechanisms of immune suppression by interleukin-10 and transforming growth factor beta: The role of T regulatory cells. Immunology. 2006;117:433-442.

39. Incorvaia C, Frati F. On mechanism of action of sublingual immunotherapy. Pediatr Allergy Immunol. 2009;20:102.

40. Noirey N, Rougier N, André C, et al. Langerhans-like dendritic cells generated from cord blood progenitors internalize pollen allergens by macropinocytosis, and part of the molecules are processed and can activate autologous naive T lymphocytes. J Allergy Clin Immunol. 2000;105:1194-1201.

41. Marcucci F, Incorvaia C, Sensi L, et al. Lack of inflammatory cells in the oral mucosa of subjects undergoing sublingual immunotherapy. Int J Immunopathol Pharmacol. 2008;21:609-613.

\section{Publish your work in this journal}

Drug Design, Development and Therapy is an international, peerreviewed open-access journal that spans the spectrum of drug design and development through to clinical applications. Clinical outcomes, patient safety, and programs for the development and effective, safe, and sustained use of medicines are a feature of the journal, which has also been accepted for indexing on PubMed Central. The manuscript management system is completely online and includes a very quick and fair peer-review system, which is all easy to use. Visit http:// www.dovepress.com/testimonials.php to read real quotes from published authors.

Submit your manuscript here: http://www.dovepress.com/drug-design-development-and-therapy-journal 